\title{
Education in Analytical Chemistry at the Universities in The Netherlands*
}

\author{
R. Visser \\ Department of Chemical Technology, Twente University of Technology, \\ NL-7500 AE Enschede, The Netherlands
}

\section{Ausbildung in Analytischer Chemie an den Universitäten der Niederlande}

Zusammenfassung. Ein Überblick wird gegeben über die gegenwärtigen Personal- und Unterrichtsverhältnisse an den verschiedenen Universitäten und Hochschulen des Landes.

Summary. In this paper a survey is presented of the actual situation with regard to the education in Analytical Chemistry at the universities in the Netherlands.

Key words: Analytische Chemie; Ausbildung in den Niederlanden.

\section{Introduction}

On behalf of the Section for Analytical Chemistry of the Royal Dutch Chemical Society (KNCV) a survey was compiled of the situation of education in Analytical Chemistry in the Netherlands. This survey is based mainly on an inquiry among the members of ISOAN (Intersubfaculty Deliberation on Analytical Chemistry in the Netherlands). In this organization all university institutes of Analytical Chemistry are represented. Part of the data has been taken from an inventory of chemistry research prepared by the Chemistry Committee of the Royal Dutch Academy of Sciences and the Foundation for Chemical Research in the Netherlands [1].

\section{Results}

In the inventory [1] the total research in chemistry, including biochemistry and chemical technology, is

\footnotetext{
* Presented at Euroanalysis III conference, Dublin, August 20-25, 1978
}

divided in 7 main streams, subdivided in 22 research areas. The 7 streams are (as reported):

- Analytical and Environmental Chemistry

- Inorganic Chemistry

- Biochemistry

- Physical Chemistry

- Organic Chemistry

- Applied Chemistry

- Others.

The Analytical and Environmental Chemistry stream is - as expected - subdivided in two areas: Analytical Chemistry and Environmental Chemistry.

In the Netherlands chemistry is taught at 6 universities, the State Universities at Leiden (RUL), Groningen (RUG) and Utrecht (RUU), the (former municipal) University of Amsterdam (UvA), the (Protestant) Free University of Amsterdam (VUA) and the Roman Catholic University at Nijmegen (KUN), furthermore at 3 technological universities, at Delft (THD), Eindhoven (THE) and in Twente (THT), and finally at the Agricultural University at Wageningen (LHW).

In Table 1 the numbers of staff members within the different main streams at the universities are presented. Only the subdivision within the first stream (Analytical and Environmental Chemistry) is given. The numbers refer to regular and temporary staff.

In Table 2 the situation in the universities with respect to the numbers of students and staff in Analytical Chemistry is specified. Total numbers of students and numbers of students specializing in Analytical Chemistry are given. It should be noted that Analytical Chemistry as a main subject can only be chosen after a preliminary non-specialized (undergraduate) study of 3-4 years. Data refer to June 1978, differences with Table 1 may therefore occur.

In Table 3 hours read in Analytical Chemistry and hours spent on practical courses are presented, both for undergraduate students and students specializing in Analytical Chemistry. These numbers do not include 
Table 1. Distribution of scientific staff over universities and main streams

\begin{tabular}{|c|c|c|c|c|c|c|c|c|c|c|c|c|}
\hline & RUL & RUG & RUU & UvA & VUA & KUN & THD & THE & THT & LHW & Others $^{\mathrm{a}}$ & Total \\
\hline Analytical Chem. & $-\mathrm{b}$ & $-^{c}$ & 34.2 & 23.3 & 6.2 & 4.0 & 10.0 & 6.3 & 5.0 & - & - & $89.0^{\circ}$ \\
\hline Environm. Chem. & - & 2.0 & - & 4.8 & - & - & 3.0 & 1.1 & 4.0 & - & - & 14.9 \\
\hline Inorganic Chem. & 33.5 & 32.0 & 40.0 & 15.5 & 13.1 & 23.7 & 24.5 & 39.7 & 17.5 & - & - & 239.5 \\
\hline Biochemistry & 60.4 & 34.8 & 39.8 & 67.5 & 16.0 & 28.0 & 27.0 & - & - & 28.7 & 128.5 & 430.7 \\
\hline Physical Chem. & 57.2 & 32.0 & 63.3 & 55.0 & 23.5 & 20.5 & - & 10.3 & 16.0 & 25.0 & 10.0 & 312.8 \\
\hline Organic Chem. & 48.0 & 35.1 & 36.6 & 59.0 & 16.3 & 19.7 & 29.5 & 23.0 & 4.3 & 16.0 & - & 287.5 \\
\hline Applied Chem. & 8.5 & 20.4 & - & 16.9 & - & - & 68.7 & 44.0 & 35.9 & 26.5 & - & 220.9 \\
\hline Others & 8.6 & 5.2 & 7.0 & 11.0 & 11.8 & 3.0 & 10.0 & - & - & 9.0 & - & 65.6 \\
\hline Total & 216.2 & 161.5 & 220.9 & 253.0 & 86.9 & 98.9 & 172.7 & 124.4 & 82.7 & 105.2 & 138.5 & 1660.9 \\
\hline
\end{tabular}

a Semi-university institutes

b At Leiden Analytical Chemistry for chemistry students is taught in the pharmacy department

- At Groningen most of the education and research of Analy tical Chemistry is carried out in the pharmacy department (exceptionally chemistry students take part)

d See Table 2 for more recent data on analytical chemistry staff

Table 2. Analytical chemistry staff and student numbers

\begin{tabular}{lllll}
\hline & $\begin{array}{l}\text { Chemistry } \\
\text { students }\end{array}$ & $\begin{array}{l}\text { Students } \\
\text { with main } \\
\text { subject } \\
\text { Anal. } \\
\text { Chem. }^{\mathrm{a}}\end{array}$ & $\begin{array}{l}\text { Acad. } \\
\text { staff at } \\
\text { analyt. } \\
\text { institutes }\end{array}$ & $\begin{array}{l}\text { Technical } \\
+ \text { adm. } \\
\text { staff } \\
\text { ibidem }^{\mathrm{c}}\end{array}$ \\
\hline RUL & $400(460)^{\mathrm{d}}$ & $2(8)^{\mathrm{d}}$ & $-(16)^{\mathrm{d}}$ & \\
RUG & 500 & 3 & 3 & $\mathrm{e}$ \\
RUU & 450 & 16 & 28 & 25 \\
UvA & 430 & 25 & $9+16.6$ & 19 \\
VUA & 400 & 16 & $3+5.5$ & 1 \\
KUN & 250 & 1 & 5 & 11 \\
THD & 420 & 10 & $11+5$ & 20 \\
THE & 400 & 14 & 11 & 11 \\
THT & 300 & 3 & 4 & 10.5 \\
\hline
\end{tabular}

a All students who have chosen the subject

b If separated by $t$ : number before $t$ is regular staff, number behind + is tempory staff (mainly those working for Ph.D.)

- Excluding central technical services and facilities

d Numbers between brackets refer to pharmacy department

- Part of larger institute

the time used for self-study. Lectures and practical work Analytical Chemistry as part of courses general chemistry and 'integrated' practical courses are mentioned separately.

In Table 4 a compilation is given of the topics dealt with in lectures and practical courses of Analytical Chemistry for all chemistry and chemical technology undergraduate students. Data presented in Roman letters refer to lectures, those in italics to practical courses.

In this table again difference is made between (pure) analytical and other courses: A $(A)$ stands for pure analytical lectures and courses, $\mathrm{G}(G)$ for Analytical
Chemistry in courses of General Chemistry, $I$ for 'integrated' practical courses and $\mathrm{O}(O)$ for courses given by other staff. (An integrated course consists wholly or mainly of experiments, each of which includes two or more aspects of chemistry, e.g. synthesis of an organic compound, followed by structure confirmation by NMR or IR and/or physical characterization such as molecular weight or magnetic susceptibility.) $G, I$ refers to an integrated course within General Chemistry, $A / I$ refers to two courses, an analytical and an integrated course.

The following subjects are treated in specialized courses for students in Analytical Chemistry.

Leiden (RUL). Electroanalysis, separation methods, analytical spectroscopy, applied statistics, titrimetric methods, pharmaceutical analysis.

Utrecht (RUU). Combined theoretical and practical courses in separation methods, elemental analysis, electroanalysis, general molecular spectrometry, mass spectrometry, infrared spectrometry, radiochemical analysis, rationalization of analytical procedures (4 courses compulsory).

Amsterdam $(U v A)$. General introduction to Analytical Chemistry and 3 topics out of the following: electrochemical analysis, radiochemical analysis, separation methods, atomic spectrometry, measuring techniques + instrumentation + data handling.

Free University Amsterdam (VUA). Separation methods, idem capita selecta, analytical spectroscopy, electroanalysis, activation analysis, environmental analysis.

Catholic University Nijmegen (KUN). General Analytical Chemistry and capita selecta (individual package). 
Table 3. Hours read in Analytical Chemistry and spent on practical courses

\begin{tabular}{|c|c|c|c|c|c|c|c|c|}
\hline & \multicolumn{5}{|c|}{ Undergraduate study } & \multicolumn{3}{|c|}{ Graduate study } \\
\hline & $\begin{array}{l}\text { Lect. } \\
\text { Anal. } \\
\text { Chem. } \\
\text { (pure) }\end{array}$ & $\begin{array}{l}\text { Idem as } \\
\text { part of } \\
\text { Gen. Chem. }\end{array}$ & $\begin{array}{l}\text { Pract. } \\
\text { courses } \\
\text { (pure) }\end{array}$ & $\begin{array}{l}\text { Idem } \\
\text { Gen. Chem. } \\
\text { incl. Anal. } \\
\text { Chem. }^{\text {a }}\end{array}$ & $\begin{array}{l}\text { Idem } \\
\text { integrated } \\
\text { chemistry }^{\mathrm{a}}\end{array}$ & $\begin{array}{l}\text { Lect. } \\
\text { Anal. } \\
\text { Chem. }\end{array}$ & $\begin{array}{l}\text { Pract. } \\
\text { courses }\end{array}$ & $\begin{array}{l}\text { Graduat. } \\
\text { work } \\
\text { (project') }\end{array}$ \\
\hline RUL & 0 & 0 & 0 & 100 & 0 & 90 & 400 & 2,000 \\
\hline RUG & 24 & 10 & 176 & 0 & 0 & 30 & 120 & 1,800 \\
\hline RUU & 46 & 0 & 320 & 0 & $300(60)$ & 160 & & 1,400 \\
\hline UvA & 68 & $9^{b}$ & 144 & 0 & $400(90-140)$ & 54 & & \\
\hline VUA & 0 & 24 & 0 & $160(40)$ & 240 & 112 & & \\
\hline KUN & 0 & 12 & 0 & 130 & 0 & 60 & 0 & 1,600 \\
\hline THD & 28 & 26 & 150 & 0 & $450(45)$ & 52 & 240 & 1,700 \\
\hline THE & 28 & 20 & 210 & 175 & 0 & $26-52$ & 210 & 1,500 \\
\hline THT & 28 & 0 & 0 & $150(90)$ & $224(60)$ & $52^{\mathrm{d}}$ & $>0^{d}$ & 1,500 \\
\hline
\end{tabular}

a Total amount; numbers in parentheses refer to the hours of Analytical Chemistry

b Organic structural analysis (by organic chemistry staff)

c Combined theoretical and practical courses

d Individual choice programme

Delft (THD). Automation in Analytical Chemistry, environmental analysis, chromatography and other separation methods, physicochemical methods for materials analysis.

Eindhoven (THE). Theory of IR and Raman, data acquisition and handling, general molecular spectrometry, mass spectrometry, clinical chemistry, applications of NMR, separation methods (contd. GLC, LLC and electrophoresis).

Twente (THT). Separation methods, titrimetry, electrochemical analysis, atomic spectroscopy, molecular spectrometry, kinetics and mechanisms in chemical analysis.

Note. Quite often one or more courses are also taken by other chemistry students. Of course not all courses listed are compulsory (number sometimes given).

The following subjects are treated in special practical courses for students in Analytical Chemistry.

Leiden. Individual package.

Groningen. Topics from environmental analysis, individual package.

Utrecht. Combined theoretical and practical courses, see above.

Amsterdam. Introduction to (mainly) radiochemistry, atomic spectrometry and measuring techniques + instrumentation + data handling.

Free University Amsterdam. Individual package.

Catholic University Nijmegen. Not applicable.

Delft. Introduction to automation (3 weeks), then instrumental methods ( 3 weeks).
Eindhoven. Choice out of GLC, LLC, isotachophoresis, mass spectrometry, NMR, IR, and applications.

Twente. Choice out of electrochemical analysis, automation and molecular spectrometry (MS, NMR, IR), individual package.

The final part of the graduate study is a 'project', lasting about one year and intended as a training for independent research work. Generally it consists of experimental work, carried out with only limited assistance, leading to a 50-100 pages report (sometimes base for a paper) and concluded by a lecture.

The Ph.D. study needs about 4 years, including up to $25 \%$ time spent on assistance in (practical) courses, and leads to a thesis ( $100-150$ pages), sometimes based on previously published papers, more often converted into papers afterwards. This work should of course be original.

Often project topics are derived from $\mathrm{Ph} . \mathrm{D}$. subjects. Therefore, in the following survey both are combined; this survey is not complete and should be considered as illustrative.

Leiden. Methods development such as elementsensitive detection in spectroscopy, after-glow emission, UV-densitometry, capillary HPLC, electrochemical detection in chromatography, H.P. puls polarography. Applications, such as mass spectrometry of pyrazolones, puls polarography of steroids, interaction between pharmaca and macromolecules, antibiotic residues in food, benzodiazepines in blood and urin, catecholamines in blood and liquor, antiepileptics in blood, chloramphenicol in milk. 
Table 4. Topics dealt with in lectures and practical courses of Analytical and General Chemistry for all chemistry (Chemical Technology) students ${ }^{\mathrm{a}}$

\begin{tabular}{|c|c|c|c|c|c|c|c|c|c|}
\hline & RUL & $\mathrm{RUG}^{\mathfrak{c}}$ & RUU & UvA & VUA & KUN & THD & THE & THT \\
\hline General Anal. Chem. ${ }^{b}$ & $\mathrm{O}$ & & & $o$ & & & A & & \\
\hline Introduction & & & & & $\mathrm{O}$ & & $\mathrm{A}$ & & \\
\hline Sampling, data handling, statistics & & & A & A & & & A & & \\
\hline Rationalization & & & A $A$ & & & & A & & \\
\hline General sep. methods ${ }^{b}$ & & $\mathrm{OO}$ & A $A$ & A & $\mathrm{O}$ & 0 & A & & A \\
\hline Destillation & & A & & A $A$ & $G, I$ & & & & \\
\hline Extraction & & & A & A & $\bigcirc G, I$ & & & & \\
\hline Distribution, counter current & & & A & $\mathrm{A}$ & $\mathrm{O}$ & 0 & & & \\
\hline Column chromatography & & A & A $A$ & A $A$ & O & O $O$ & A & A $A$ & \\
\hline Paper chromatography & & & & & $\mathrm{O}$ & OO & $\mathrm{A}$ & A $A$ & \\
\hline Thin-layer chromatography & $G$ & & $A$ & $I$ & $\mathrm{O} G, I$ & $\mathrm{O}$ & A $A$ & A $A$ & $\mathrm{~A}$ \\
\hline Gas-liquid chromatography & & & A $A$ & A $A$ & $\mathrm{O}$ & 0 & A $A / I$ & $\mathrm{~A} A$ & A $I$ \\
\hline Electrophoresis & & & $A$ & $A$ & $\mathrm{O} G, I$ & $O$ & & $\mathrm{~A} A$ & \\
\hline Ion exchange & & & $A$ & & $O G, I$ & $\mathrm{O}$ & & & \\
\hline General solution analysis ${ }^{b}$ & & $o$ & A & $\mathrm{A}$ & $\mathrm{O}$ & & & & $\mathrm{A}$ \\
\hline Gravimetry & & & & $\mathrm{A}$ & O $G, I$ & & & OG & \\
\hline Titrimetry & $G$ & $\mathrm{~A}$ & A $A$ & A $I$ & O $G, I$ & & O $A$ & $\mathrm{OG}$ & $\mathrm{A}$ \\
\hline General electroanalysis & & & A $A$ & A $I$ & $\mathrm{O} G, I$ & $\mathrm{O}$ & & $\mathrm{O}$ & \\
\hline Conductometry & $O$ & A & A & A $I$ & $\circ G, I$ & O O & & $G$ & $G$ \\
\hline Potentiometry & $O$ & $\mathrm{~A}$ & A $A$ & A $I$ & $O G, I$ & O O & & $G$ & A $I / G$ \\
\hline Polarography & & & A $A$ & & & O O & $I$ & & \\
\hline Absorptiometry & $G$ & & A $A$ & $I$ & $\bigcirc G, I$ & O $O$ & O $A$ & & \\
\hline Functional group analysis & & & & & & & & & A \\
\hline Microelemental analysis & & & & & & & & & $A$ \\
\hline General atomic spectrometry ${ }^{b}$ & & & & & & & A & & $\mathrm{A}$ \\
\hline Atomic emission spectrometry & & & A $A$ & & $\mathrm{O}$ & O $O$ & A $I$ & & A \\
\hline Atomic absorption spectrometry & & & $\mathrm{A} A$ & & & $\mathrm{O}$ & A & & A $I$ \\
\hline X-ray fluorescence & & & A & & & & A & & $\mathrm{A}$ \\
\hline General molecular spectrometry ${ }^{\mathrm{b}}$ & O $O$ & & A $A$ & $\mathrm{O}$ & o & $o$ & & $A$ & A $I$ \\
\hline UV/VIS spectrometry & $O$ & & A $A$ & $\mathrm{O}$ & $O$ & $O$ & & $A$ & A $I$ \\
\hline IR (Raman) spectrometry & $O$ & O $O$ & $\mathrm{~A} A$ & $\mathrm{O}$ & $O$ & $O$ & O $A$ & $A$ & A $I$ \\
\hline Nuclear magnetic resonance & $O$ & $\mathrm{O}$ & A & $\mathrm{O}$ & & $O$ & $I$ & $A$ & A $I$ \\
\hline Mass spectrometry & $O$ & $\mathrm{O}$ & A $A$ & $\mathrm{O}$ & & & $I$ & $A$ & $\mathrm{~A}$ \\
\hline Physical constants & & & & & & & & & $I$ \\
\hline Osmometry & $O$ & & & & & & & & \\
\hline Viscosimetry & $O$ & & & & & & & & \\
\hline Anal. radiochemistry & & & A $A$ & $\mathrm{~A} A$ & A & $O$ & & & \\
\hline Thermal analysis & & & A & & & & & & \\
\hline
\end{tabular}

a See text for explanation of used code

b 'General' stands for: broad, not too profound survey

- Major changes in progress

Groningen. Determination of low concentrations of heavy metals, ion-selective electrodes, determination of 'aerosol' sulphuric acid in air.

Utrecht. Topics in separation methods, elemental analysis, electroanalysis, mass spectrometry, IR/Raman spectrometry, radiochemical analysis and rationalization of analytical procedures.

University of Amsterdam. Activation analysis (trace analysis, analysis of nail coups, analysis of dried biological material, radiotracers in flameless AAS); chromatography (phase systems, theoretical and practical evaluation of correlation chromatography, optimization, dispersion in chromatography, postcolumn reaction detection and electrochemical detection in HPLC, and analytical, clinical and environmental applications such as analysis of body fluids with HPLC); electrochemistry [ion selective electrodes, (pulse) voltammetric techniques]; atomic spectrometry (fundamental and practical aspects of flameless AAS, atomic spectrometric analysis of trace metals, inductively coupled argon plasma, laser microprobe); fundamentals (computer simulation of analytical procedures, evaluation of errors in chemical analysis, pattern recognition). 
Free University Amsterdam. HPLC and TLC, pre-, onand post-column derivatization, selective sample cleanup and preconcentration methods, i.e. on solid surfaces, fluorescence and phosphorescence and electrochemical detection in continuous-flow systems. Applications in the environmental and pharmaceutical field.

Catholic University Nijmegen. Quality control in clinical laboratories, analysis for dynamic process control, process control with Kalman filtering, optimization of analytical laboratories via digital simulation, pattern recognition, on-line optimization of analytical apparatus.

Delft. Chromatography (gradient elution in HPLC, retention mechanisms in HPLC, chemically bonded stationary phases); atomic spectroscopy (ICP radiofrequency plasma atomic emission, Zeeman atomic absorption, MIP microwave plasma atomic spectroscopy); automation (retrieval system for MS, automatic measurements in chemical reactors); applications (determination of organic compounds in water).

Eindhoven. Topics from chromatography (GLC, HPLC, isotachophoresis) and molecular spectrometry
(MS, NMR, IR); applications (a.o. clinical determinations).

Twente. Computerization of polarography and potentiometry, molecular spectrometry of unsaturated aromatic compounds.

Finally, it should be mentioned that especially education and research in radiochemical analysis (activation analysis) is carried out in co-operation with independent institutes such as Energy Research Center (Petten) or Institute for Nuclear Physics Research (Amsterdam).

Acknowledgement. The author is indebted to members of ISOAN for their assistance in preparing this survey.

\section{Reference}

1. Inventory of Chemical Research at Universities and Technological Universities, Chemistry Commission of the Royal Dutch Academy of Sciences and Foundation for Chemical Research in the Netherlands, Amsterdam, The Hague, 1977 (in Dutch).

Received December 3, 1978 